\title{
Modeling Menaquinone 7 production in tray type solid state fermenter
}
Raja Mahanama ${ }^{1}$
Aydin Berenjian $^{2}$
Andrea Talbot ${ }^{4}$
Fariba Dehghani ${ }^{5}$
Hub Regtop ${ }^{3}$
John Kavanagh ${ }^{6}$

(Received 9 January 2012; revised 19 June 2012)

\begin{abstract}
The fermented Japanese food Natto contains menaquinone 7 which is known to reduce the incidence of bone fractures and cardio vascular diseases. Natto is traditionally produced by the solid state fermentation of soy beans by Bacillus subtilis natto. A mathematical model is developed for describing the production of menaquinone 7 in a static solid substrate bed supported on a tray fermenter using parameters obtained from literature for similar micro-organisms. Two model parameters were fitted to experimental data obtained to predict menaquinone 7 production. The postulated model presented in the form of a sensitivity analysis is likely to yield valuable insights on the dynamic behaviour of bacterial kinetics, including the formation of products such as menaquinone 7 as the first step towards scaling up.
\end{abstract}

http://journal .austms.org.au/ojs/index.php/ANZIAMJ/article/view/5103 gives this article, (c) Austral. Mathematical Soc. 2012. Published July 14, 2012. ISSN 1446-8735. (Print two pages per sheet of paper.) Copies of this article must not be made otherwise available on the internet; instead link directly to this URL for this article. 


\section{Contents}

1 Introduction

C355

1.1 Model development . . . . . . . . . . . . . . . . . C356

1.1.1 Basic kinetic equations . . . . . . . . . . . C356

1.1.2 The effect of environmental conditions on growth . C357

1.1.3 Death kinetics . . . . . . . . . . . . . C358

1.1.4 Product formation . . . . . . . . . . . . . C359

1.1.5 $\mathrm{CO}_{2}$ production and $\mathrm{O}_{2}$ consumption . . . . . . C359

2 Materials and methods $\quad$ C360

2.1 Microoganism . . . . . . . . . . . . . . . C360

2.2 Inoculum . . . . . . . . . . . . . . . . . . C360

2.3 Medium .................... . . C360

2.4 Substrate preparation and fermentation . . . . . . . C C360

2.5 MK7 extraction and determination . . . . . . . . . . C C361

2.6 Parameters and assumptions . . . . . . . . . . . . C361

3 Results and discussion $\quad$ C362

4 Conclusions $\quad$ C367

References

C368

\section{Introduction}

Menaquinone 7 (MK7) is part of the family known as vitamin $K_{2}$, and is necessary for the synthesis of blood coagulation factors, the activation of proteins involved in the building of bones and inhibition of vascular calcification $[1,2]$. Solid state fermentation (SSF) of MK7 in static bed reactors has only been the subject of limited research $[3,4,5,6,7,25]$, where the relevant phenomena are yet to be fully understood; hence mathematical models play an important 
role in fermenter design, optimization and potential scale up. This study proposes a model for an overall performance of a bioreactor. This mathematical model consists of transport phenomena and microbial kinetics to estimate the effects of environmental conditions on MK7 production. Shallow trays have a maximum bed thickness of $1 \mathrm{~cm}$ to avoid the $\mathrm{O}_{2}$ transfer resistance. The set up used for collecting experimental data was designed in house and the model predicted the effect of process parameters on the biomass growth and production of MK7.

\subsection{Model development}

The model is a set of four balanced equations. The lumped parameter model describes the production of MK7 via Bacillus subtilis in tray type fermenters.

\subsubsection{Basic kinetic equations}

Mathematical models of SSF bioreactors are commonly based on logistic equations [8]. These equations rely on a simplification of mathematical modeling by employing a single equation for estimating the whole growth rate profile including the lag phase and cessation of growth in the last stage of fermentation. This simplified differential equation,

$$
\frac{d X}{d t}=\mu X\left(1-\frac{X}{X_{m}}\right),
$$

eradicates the need for an additional equation for substrate measurement and estimating the parameters of SSF [9]. Here, $\boldsymbol{X}$ is microbial biomass, $\boldsymbol{t}$ is time, $\mu$ is the specific growth rate constant, and $X_{m}$ is the maximum possible microbial biomass. 


\subsubsection{The effect of environmental conditions on growth}

The two most important environmental variables that have significant impact on bioreactor operation are temperature and the water activity for the fermentation bed. The constant condition approach determines the effect of these environmental variables in the model,

$$
\mu_{\mathrm{T}}=\frac{A \exp \left[\frac{-E_{a 1}}{\mathrm{R}(\mathrm{T}+273)}\right]}{1+\mathrm{B} \exp \left[\frac{-E_{a 2}}{\mathrm{R}(\mathrm{T}+273)}\right]},
$$

where $A$ and $B$ are dimensionless, $E_{a 1}$ and $E_{a 2}$ fitting parameters, $R$ is the universal gas constant, $T$ is temperature, and $\mu_{T}$ is the effect of temperature on specific growth rate parameter. The assumption of an isothermal system was used to develop the model for determining the effect of temperature. A similar concept was also applied by von Meien and Mitchell [11] for predicting the effect of water activity on bacterial growth which can be depicted as

$$
\frac{\mu_{W}}{\mu_{\mathrm{opt}}}=\exp \left[\mathrm{D}_{1}\left(\mathrm{a}^{3}\right)_{\mathrm{ws}}+\mathrm{D}_{2}\left(\mathrm{a}^{2}\right)_{\mathrm{ws}}+\mathrm{D}_{3}(\mathrm{a})_{\mathrm{ws}}+\mathrm{D}_{4}\right],
$$

where $D_{1}$ to $D_{4}$ are fitting parameters, $a_{w s}$ is water activity of the solid substrate phase, $\mu_{W}$ is the effect of water activity on the specific growth rate parameter, and $\mu_{\mathrm{opt}}$ is the optimum specific growth rate parameter. In subsequent equations we use the true specific growth rate $\mu_{\mathrm{G}}$ [12], which is the geometric mean of the temperature and water activity specific growth rate parameters:

$$
\mu_{\mathrm{G}}=\sqrt{\mu_{W} \mu_{T}} .
$$

To date, most models of SSF bioreactors used this approach to describe the effect of environmental conditions on the parameters of the growth equation $[10,12,13,14]$ although the form of the empirical equation that is used varies. In any case, use of these equations within the kinetic submodel of a bioreactor model has the implicit assumption that the growth of the microorganism depends only on the current values of the environmental variables. 


\subsubsection{Death kinetics}

In SSF bioreactors, the environmental conditions, especially the temperature, can attain values that are sufficiently adverse to cause death [15]. The modeling of death kinetics in SSF systems has received relatively little attention due to a problematic definition of death via measuring it experimentally through total and viable counts [15].

If death is simply defined as a permanent loss of the ability to grow, then autolysis is not a necessary consequence of death. Therefore death will not necessarily lead to a reduction in the amount of biomass, so it is not a simple matter to quantify death experimentally. As a result, current models of death used in SSF bioreactor models are very simple. For example, Sangsurasak and Mitchell [16] assumed first order death kinetics and segregated the microbial biomass into living and dead sub-populations:

$$
\begin{aligned}
& \frac{d X_{V}}{d t}=\mu_{G} X_{V}\left(1-\frac{X_{V}+X_{D}}{X_{m}}-k_{D} X_{V}\right), \\
& \frac{d X_{D}}{d t}=k_{D} X_{V},
\end{aligned}
$$

where $X_{V}$ is viable cells, $X_{D}$ is dead cells, $\mu_{G}$ is true specific growth rate, and $k_{D}$ is specific death rate coefficient.

It is not a simple matter to determine the true specific growth rate and the first order death constant $\left(k_{\mathrm{D}}\right)$ for use in these equations. We employed the equation proposed by Szewczyk and Myszka [17] by fitting two Arrhenius-type terms to a plot of observed specific growth rate versus temperature $[15,16]$,

$$
\mu_{\text {obs }}=\mu_{G}-k_{D}=\mu_{G}-k_{D_{0}} \exp \left(-\frac{E_{a_{D}}}{R T}\right),
$$

where $k_{D}$ and $k_{D_{0}}$ are frequency factors, $E_{a_{D}}$ is activation energy of death kinetic, respectively; and $\mu_{\mathrm{obs}}$ is used as $\mu$ in Equation (1). 


\subsubsection{Product formation}

MK7 production is assumed to be of the form,

$$
r_{P}=\frac{d P}{d t}=Y_{P X} \frac{d X}{d t}+m_{p} X
$$

where $r_{P}$ is overall rate of product formation, $Y_{P X}$ is growth associated product formation rate (fitted parameter), and $m_{\mathrm{P}}$ is nongrowth associated product formation rate (fitted parameter).

\subsection{5 $\mathrm{CO}_{2}$ production and $\mathrm{O}_{2}$ consumption}

The consumption of $\mathrm{O}_{2}$ and $\mathrm{CO}_{2}$ production are estimated by

$$
\begin{aligned}
& \frac{d C O_{2}}{d T}=\mu\left(\frac{X}{Y_{X / \mathrm{CO}_{2}}}\right)+m_{\mathrm{CO}_{2}} X, \\
& \frac{d O_{2}}{d T}=\mu\left(\frac{X}{Y_{X / O_{2}}}\right)-m_{\mathrm{O}_{2}} X,
\end{aligned}
$$

where $\mathrm{Y}_{\mathrm{X} / \mathrm{CO}_{2}}$ is the yield of $\mathrm{CO}_{2}$ from biomass, $\mathrm{Y}_{\mathrm{X} / \mathrm{O}_{2}}$ is the yield of biomass from $\mathrm{O}_{2}$, and $\mathrm{m}_{\mathrm{O}_{2}} / \mathrm{m}_{\mathrm{CO}_{2}}$ are maintenance coefficients. Equation (10) can be used to indirectly measure the evolution of heat which affects the temperature and hence the specific growth rate $(\mu)$ shown in Equation (2). Additionally, $\mathrm{O}_{2}$ consumption and $\mathrm{CO}_{2}$ evolution are of particular interest in model postulation, since they represent the most convenient way of estimating the growth parameters in a bioreactor, and are the focus of upcoming experiments. Equations were solved using Simulink ode15s. 


\section{Materials and methods}

\subsection{Microoganism}

Strain Bacillus subtilis var. natto was isolated from commercially available natto after screening different types for highest MK7 producing strain as described by Berenjian et al. [18].

\subsection{Inoculum}

Spores of Bacillus subtilis incubated on a liquid culture were suspended in $0.9 \% \mathrm{NaCl}$ solution to obtain the standard spore solution of $10.8 \pm$ $\left.0.04 \log \mathrm{CFU} \mathrm{gm}^{-1}\right)$. Solid state fermentation was carried out in square type Petri dishes $(100 \mathrm{~mm} \times 100 \mathrm{~mm} \times 15 \mathrm{~mm}$, Greiner, Germany) with a spore loading of $8.4 \pm 0.04 \log \mathrm{CFU} \mathrm{gm}^{-1}$.

\subsection{Medium}

An equal mixture of corn and soy was autoclaved in the absence of water at $121^{\circ} \mathrm{C}$ for 20 minutes before inoculation. The water content after inoculation was adjusted to $70 \%$.

\subsection{Substrate preparation and fermentation}

Substrates used in this experiment were nixtamalized corn grits and soy protein granules. These substrates were employed in a mixture of equal corn and soy without any supplementation with other carbon and nitrogen sources. The SSF procedure used has been described previously [6]. Briefly, the initial moisture content was adjusted at $50 \%$ by addition of sterilized 
water to the autoclaved substrate that was kept in a fridge $\left(4^{\circ} \mathrm{C}\right)$ overnight to allow complete swelling of the granules. Fermentation was carried out at $37^{\circ} \mathrm{C}$ inside an unaerated chamber (Thermoline Scientific, Australia) where relative humidity was maintained at $90-95 \%$ to minimize water evaporation from the substrate bed. The relative humidity, temperature and dew point were measured throughout the incubation period using a data logger (Lascar Electronics, UK). The production of MK7 was measured on days three, five and seven during the fermentation. Individual sample trays were prepared for each day to extract MK7 to minimize error in sampling and measurement.

\subsection{MK7 extraction and determination}

MK7 was extracted from $3 \mathrm{gm}$ of homogenized wet substrate using $12 \mathrm{~mL}$ 2-propanol: n-hexane (v:v 1:2) and determined using high performance liquid chromatography (HP 1050, Hewlett-Packard, USA) using the method described in detail previously [18]. The LC-MS system (LCMS-2010EV, Shimadzu, Kyoto) was used to confirm the structure of MK7 [18].

\subsection{Parameters and assumptions}

The critical parameters for Bacillus subtilis do not exist in the literature. Therefore, the parameters listed in Table 1 for other microorganisms were used to estimate the constants for the equations for Bacillus subtilis fermentation. Microbiological research relies on the use of model organisms that act as representatives of their species or subspecies, these are frequently well-characterized laboratory strains. However, it has often become apparent that the model strain initially chosen may not represent important features of the species [26].

- Heat evolution is assumed to be $460 \mathrm{~kJ} \mathrm{~mol}^{-1} \mathrm{O}_{2}\left(14.375 \mathrm{~kJ} \mathrm{gm}^{-1} \mathrm{O}_{2}\right)$ [21].

- Enthalpy of evaporation of $\mathrm{H}_{2} \mathrm{O}$ assumed to be $2 \mathrm{MJ} \mathrm{kg}^{-1}$ of $\mathrm{H}_{2} \mathrm{O}$ [22]. 
Table 1: Coefficient values and model microorganisms (where appropriate, values have been converted from the units used by the cited source).

\begin{tabular}{llllc}
\hline coeff. & value* & model strain & Ref & Eqn \\
\hline $\mathrm{A}$ & $2.694 \times 10^{11} \mathrm{~h}^{-1}$ & Aspergillus niger & {$[10]$} & $(2)$ \\
$\mathrm{B}_{1}$ & $3 \times 10^{47}$ & Aspergillus niger & {$[10]$} & $(2)$ \\
$\mathrm{A}_{\mathrm{a} 1}$ & $70225 \mathrm{~J} \mathrm{~mol}^{-1}$ & Aspergillus niger & {$[10]$} & $(2)$ \\
$\mathrm{E}_{\mathrm{a} 2}$ & $283356 \mathrm{~J} \mathrm{~mol}^{-1}$ & Aspergillus niger & {$[10]$} & $(2)$ \\
$\mathrm{D}_{1}$ & 618.92 & Aspergillus niger & {$[19]$} & $(3)$ \\
$\mathrm{D}_{2}$ & -1863.53 & Aspergillus niger & {$[19]$} & $(3)$ \\
$\mathrm{D}_{3}$ & 1865.1 & Aspergillus niger & {$[19]$} & $(3)$ \\
$\mathrm{D}_{4}$ & -620.67 & Aspergillus niger & {$[19]$} & $(3)$ \\
$\mathrm{Y}_{\mathrm{X} / \mathrm{CO}_{2}}$ & $0.76394 \mathrm{~kg} \mathrm{CO}_{2} \mathrm{~kg} \mathrm{X}^{-1}$ & Rhizopus sp. & {$[12]$} & $(9)$ \\
$\mathrm{m}_{\mathrm{c}}$ & $0.031 \mathrm{~kg} \mathrm{CO}_{2} \mathrm{~kg} \mathrm{X}^{-1} \mathrm{~h}^{-1}$ & Rhizopus sp. & {$[12]$} & $(9)$ \\
$\mathrm{Y}_{\mathrm{X} / \mathrm{O}_{2}}$ & $0.9510 \mathrm{~kg} \mathrm{X} \mathrm{kg} \mathrm{O}_{2}^{-1}$ & Gibberella fujikori & {$[20]$} & $(10)$ \\
$\mathrm{m}_{\mathrm{O}_{2}}$ & $0.013 \mathrm{~kg} \mathrm{O}_{2} \mathrm{~kg} \mathrm{X}^{-1} \mathrm{~h}^{-1}$ & Gibberella fujikori & {$[20]$} & $(10)$ \\
\hline
\end{tabular}

- Oxygen transfer resistance is negligible.

- Unlimited substrate availability (nitrogen and carbon sources).

- Temperature and water activity $\left(\mathbf{a}_{w}\right)$ remain constant throughout cultivation.

- Model parameters remain constant throughout cultivation.

- Shikimate pathway for MK7 production was neglected.

\section{$3 \quad$ Results and discussion}

SSF modeling is challenging due to the heterogeneous nature of fermentation and lack of available data for microorganisms of interest. Additionally possible 


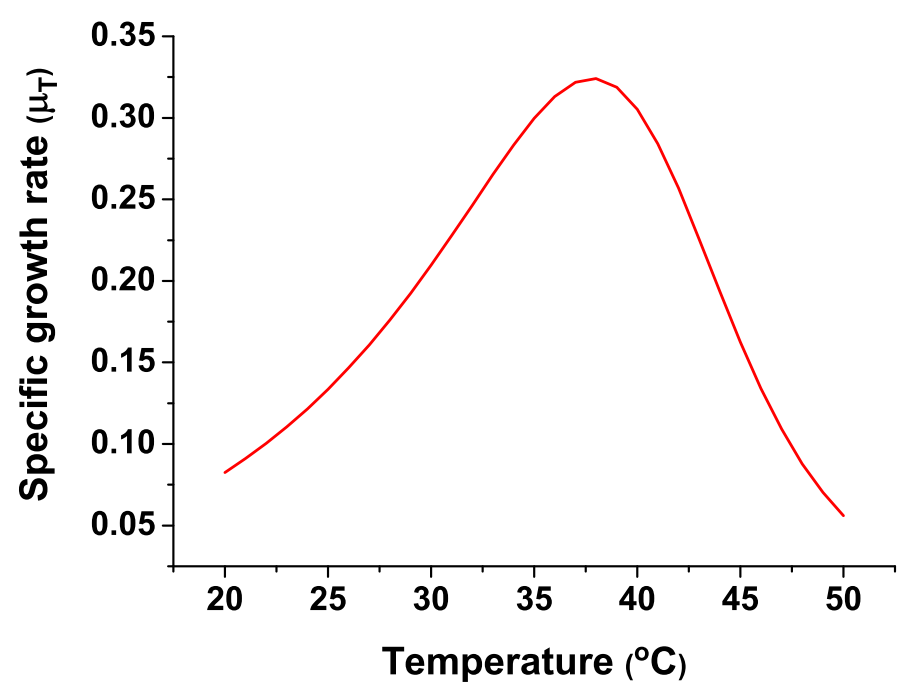

Figure 1: Dependence of specific growth rate upon temperature.

deviations are expected since the dissimilarity of fitting parameters obtained by different model microorganisms. The kinetic submodel is described including the dependency on key environmental variables, because these variables typically cannot be simply controlled at their optimum values in a SSF bioreactor [8].

The effects of temperature and water activity on growth are described in Figures 1 and 2, by expressing the parameters in the kinetic equation as functions of the local conditions. These functions were calculated assuming "isothermal" and "isohydric" conditions, which were maintained throughout the growth cycle, whereas in real SSF processes the temperature and the water activity change during the process. It is possible that expressions for the effects of temperature and water activity that were obtained from isothermal and isohydric assumptions cannot describe the true effect on growth of the time varying conditions that are encountered by the organism in SSF processes at large scales [23].

According to Equation (2) the effect of the specific growth rate parameter $\mu$ 


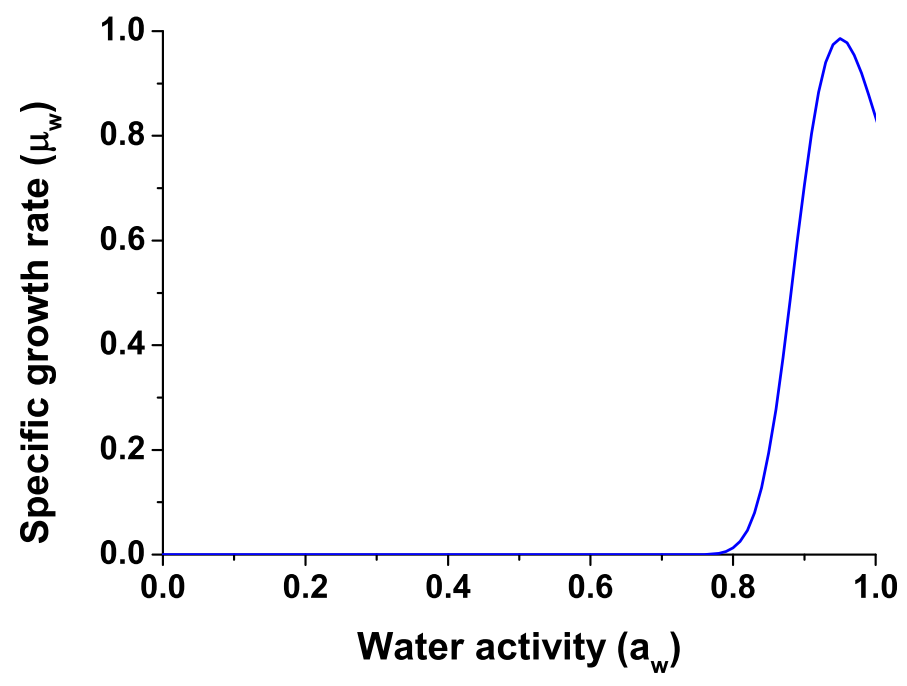

Figure 2: Dependence of specific growth rate upon water activity.

on temperature is described using the double-Arrhenius equation of SaucedoCastaneda et al. [10]. The symbol $\mu_{\mathrm{T}}$ denotes that the equation describes specifically the effect of temperature on the specific growth rate parameter. The dependence of the specific growth rate parameter $\mu_{W}$ on water activity was described by Equation (3) of von Meien and Mitchell [11], and the geometric mean of the individual specific growth rates were calculated for their combined effect in Equation (4).

The variation of MK7 production during the cultivation at $37^{\circ} \mathrm{C}$ and $\mathrm{a}_{w}$ of 0.95 is presented in Figure 3, in which the solid line represents the estimation from the model by fitting the experimental data and adjusting growth associated product formation $\left(Y_{P X}\right)$ and nongrowth associated product formation rate $\left(m_{P}\right)$. There was a good agreement between experimental data and results predicted by the model. The data in Figure 4 shows that by increasing the temperature from $35^{\circ} \mathrm{C}$ to $45^{\circ} \mathrm{C}$ the yield of $\mathrm{MK} 7$ decreased by $40 \%$. The predicted value for MK7 production by the model was $140 \mathrm{mg} \mathrm{kg}^{-1}$ within the temperature range $35^{\circ} \mathrm{C}$ to $37^{\circ} \mathrm{C}$, which is similar to value acquired 


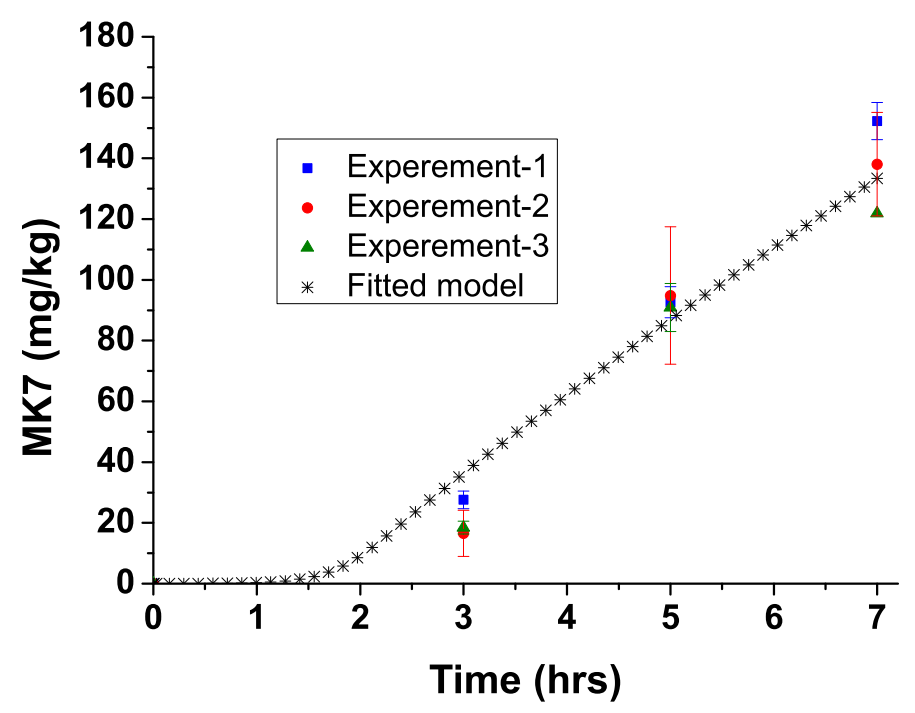

Figure 3: Model estimation versus experimental values.

by Mahanama et al. $[5,6,7]$ using experimental data and response surface methodology.

The effect of water activity on the production of $\mathrm{MK} 7$ at $37^{\circ} \mathrm{C}$ is shown in Figure 5. The results of our study demonstrate that the high moisture content is critical for the production of MK7 and its production ceased when the moisture content dropped below $80 \%$. This data shows that bacteria growth in SSF is different from fungi that can grow even at lower moisture content such as 50\% humidity [24]. The low moisture level dries the culture and decreases the growth rate, subsequently dropping the MK7 yield. The production of MK7 was enhanced for all solid substrates with the initial moisture level of $70 \%$ when using static fermentations [6]. According to Lonsane et al. [25] only limited water is used in SSF, but water exhibits profound effects on the physicochemical properties of solids, which in turn affects process productivities. Different models were used to investigate the effect of water activity and moisture on fermentation and MK7 production. Our results shows the significant impact of water activity on MK7 production. 


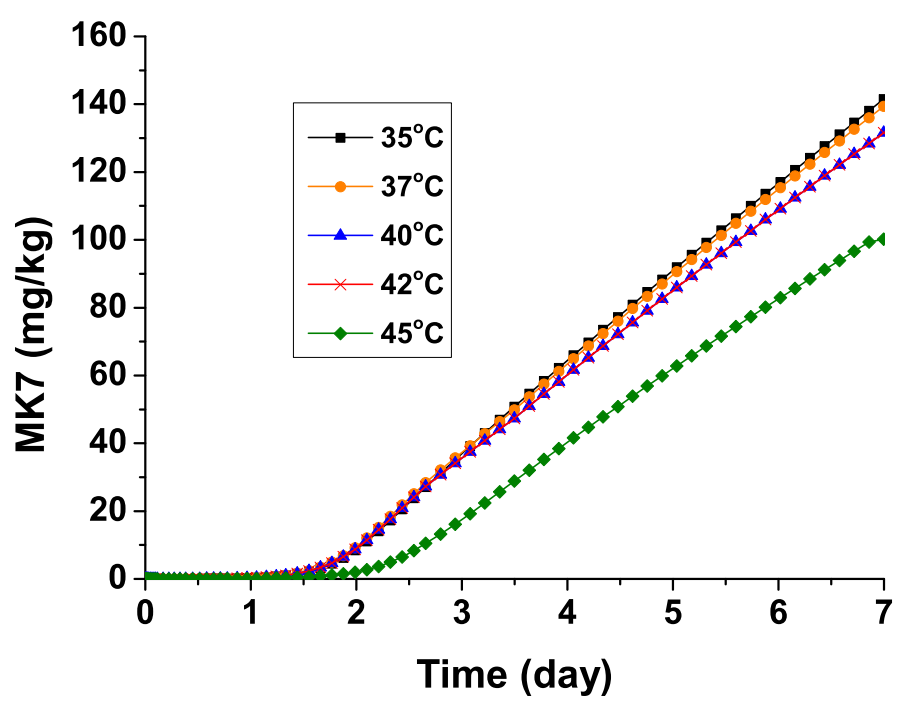

Figure 4: The effect of temperature on MK7 production

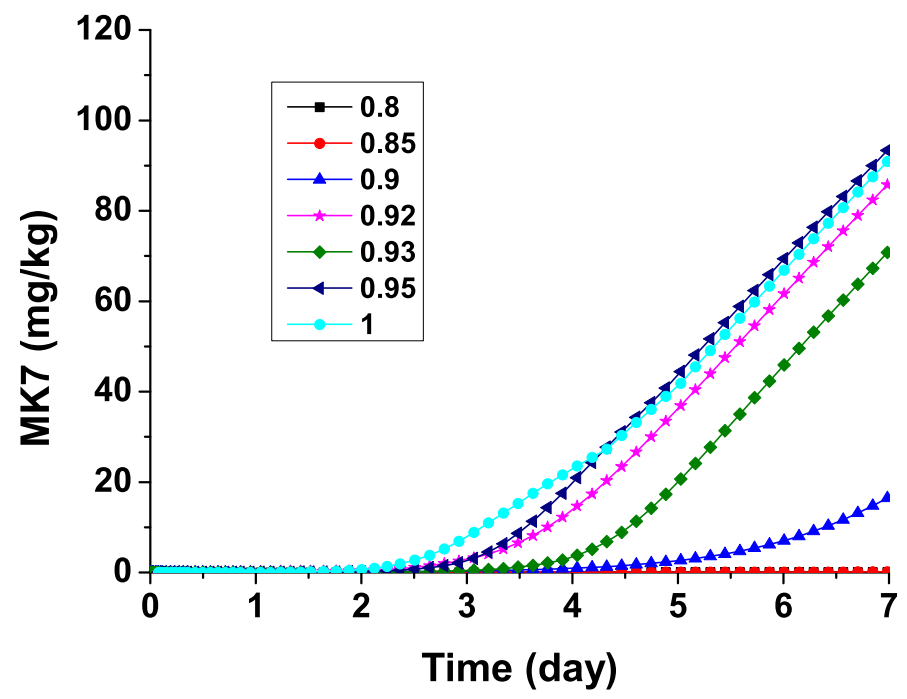

Figure 5: The effect of water activity on MK7 production 


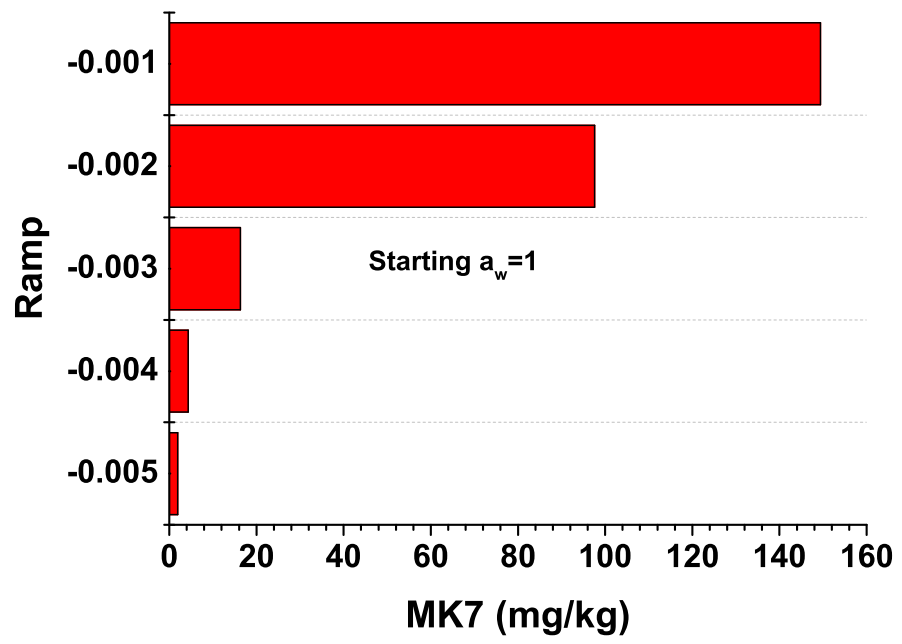

Figure 6: Predicted MK7 concentrations in reducing water activities

As shown in Figure 6, the MK7 recovery at the end of fermentation was decreased with a reducing ramp that was associated with a faster moisture evaporation rate. The model predicted the MK7 concentration of $150 \mathrm{mg} \mathrm{kg}^{-1}$ at the lowest level of moisture content reduction (that is, -0.001). The postulated MK7 concentration was dropped below $12 \mathrm{mg} \mathrm{kg}^{-1}$ when the ramp increased fivefold. At the end of the fermentation period the moisture contents for ramps -0.001 and -0.005 were $83 \%$ and $16 \%$, respectively. These results are in good agreement with our previous data in which the sudden drop of moisture content within the range of $10 \%$ to $20 \%$ dramatically decreased MK 7 production to $80 \%$ [6].

\section{Conclusions}

The mathematical model developed in this study is based on parameters from Gibberella fujikori, Aspergillus niger and Rhizopus sp. microoganisms. The model could be matched to measurements, and qualitatively predict the effect 
on drying in MK7 production via a solid sate static bed fermenter. Water activity had a significant impact on MK7 production; however, temperature had a negligible effect within the range examined. The evaporation of water from the substrate bed had an adverse effect on MK7 production due to the drying and shrinkage of the bed. The proposed model has the potential to be used for developing a tray type bioreactor with a thicker bed for the production of MK7. Further research is required in a broader range to determine the effects of process parameters on the growth rate of microorganisms and MK7 production.

Acknowledgements We gratefully acknowledge the Australian Research Council through an ARC Linkage Project (LP100100347) for financial support.

\section{References}

[1] F. Brug and T. Bacchetti F. and Principi and G. Paolo and L. Littarru Tiano. Olive oil supplemented with menaquinone-7 significantly affects osteocalcin carboxylation. British Journal of Nutrition 1, 1-5, 2011. doi:doi:10.1017/S0007114511001425 C355

[2] K. Rheaume-Bleue. Vitamin $\mathrm{K}_{2}$ and the Calcium Paradox: How a Little-Known Vitamin Could Save Your Life Wiley, 2012. C355

[3] H. Sumi and N. Asano and C. Yatagai Additional effect of some nutrients and biological-active substances by Bacillus natto treatment of raw wheat. Journal of the Brewing Society of Japan 100, 449-453, 2005. http://sciencelinks.jp/j-east/display.php?id= 000020051405 A0583674 C355

[4] C. H. Wu and C. C. Chou. Enhancement of aglycone, vitamin K2 and superoxide dismutase activity of black soybean through fermentation with Bacillus subtilis BCRC 14715 at different temperatures. Journal of 
agricultural and food chemistry 57, 10695-10700, 2009. doi:10.1021/jf902752t C355

[5] R. Mahanama and A. Berenjian and P. Valtchev and H. Regtop and R. Biffin and A. Talbot and F. Dehghani and J. Kavanagh. Enhanced Production of Menaquinone 7 via Solid Substrate Fermentation from Bacillus subtilis. International Journal of Food Engineering 7( 5), 1-23, 2011. doi::10.2202/1556-3758.2314 C355, C365

[6] R. Mahanama and A. Berenjian and H. Regtop and R. Biffin and A. Talbot and F. Dehghani and J. Kavanagh. Solid-substrate Fermentation of Vitamin K2 with Bacillus Subtilis: Comparison of Continuous Rotation with Stationary bed Fermentation in different Initial Moisture Levels. Chemeca, Sydney Australia 18-21 September 2011 wWw. conference.net.au/chemeca2011/papers/106.pdf C355, C360, C365, C367

[7] R. Mahanama and A. Berenjian and F.Dehghani and J. M. Kavanagh. Effects of Inoculation Loading and Substrate Bed Thickness on the Production of Menaquinone 7 via Solid State Fermentation. Lecture Notes in Engineering and Computer Science: Proceedings of The World Congress on Engineering and Computer Science 2011, WCECS 2011, 19-21 October, 2011, San Francisco, USA, 694-697 wWw. iaeng.org/publication/.../WCECS2011_pp694-697.pdf C355, C365

[8] D. A. Mitchell and N. Krieger and M. Berovic. Solid-State fermentation bioreactors, Fundamentals of design and operation. Elsevier 2006. C356, C363

[9] G. Viccini and D. A. Mitchell and S. D. Boit and J. Gern and A. S. da Rosa and R. M. Costa and F. D. H. Dalsenter and O. F. von Meien and N. Krieger. Analysis of growth kinetic profiles in solid-state fermentation. Food Technology and Biotechnology 39 271-294, 2001. doi:663.143:579.24.57.037 C356 
[10] G. Saucedo-Castaeda and M. Gutirrez-Rojas and G. Bacquet and M. Raimbault and G. Viniegra-Gonzlez. Heat transfer simulation in solid substrate fermentation. Biotechnology and bioengineering 35, 802-808, 1990. doi:10.1002/bit.260350808 C357, C362, C364

[11] O. F. Von Meien and D. A. Mitchell. A two-phase model for water and heat transfer within an intermittently-mixed solid-state fermentation bioreactor with forced aeration. Biotechnology and bioengineering 79, 416-428, 2002. doi:10.1002/bit.10268 C357, C364

[12] J. Sargantanis and M. N. Karim and V. G. Murphy and D. Ryoo and R. P. Tengerdy. Effect of operating conditions on solid substrate fermentation. Biotechnology and bioengineering 42, 149-158, 1993. doi:10.1002/bit.10268 C357, C362

[13] S. Rajagopalan and J. M. Modak. Heat and mass transfer simulation studies for solid-state fermentation processes. Chemical engineering science 49, pp. 2187-2193, 1994. doi:10.1016/0009-2509(94)E0012-F $\mathrm{C} 357$

[14] D. A. Mitchell and O. Von Meien. Mathematical modeling as a tool to investigate the design and operation of the zymotis packed-bed bioreactor for solid-state fermentation. Biotechnology and bioengineering 68 127-135, 2000. doi:10.1002/(SICI)1097-0290(20000420)68:2ز127::AIDBIT1;3.0.CO;2-K

C357

[15] D. A. Mitchell and O. F. von Meien and N. Krieger and F. D. H. Dalsenter A review of recent developments in modeling of microbial growth kinetics and intraparticle phenomena in solid-state fermentation. Biochemical Engineering Journal 17 15-26, 2004. doi:10.1016/S1369-703X(03)00120-7 C358

[16] P. Sangsurasak and D. A. Mitchell. Incorporation of death kinetics into a 2-dimensional dynamic heat transfer model for solid state 
fermentation. Journal of Chemical Technology and Biotechnology 64 253-260, 1995. doi:10.1002/jctb.280640307 C358

[17] K. Szewczyk and L. Myszka. The effect of temperature on the growth of A. niger in solid state fermentation. Bioprocess and Biosystems Engineering 10, 123-126, 1994. doi:10.1007/BF00369467 C358

[18] A. Berenjian and R. Mahanama and A. Talbot and R. Biffin and H. Regtop. and P. Valtchev and J. M. Kavanagh and F. Dehghani. Efficient media for high menaquinone-7 production: Response surface methodology approach., New Biotechnology 28 (6), 665-672, doi:10.1016/j.nbt.2011.07.007 C360, C361

[19] D. Glenn and P. Rogers. A solid substrate fermentation process for an animal feed product: Studies on fungal strain improvement. Australian Journal of Biotechnology 2, 50-54, 1988. C362

[20] J. Thibault and K. Pouliot and E. Agosin and R. Prez-Correa. Reassessment of the estimation of dissolved oxygen concentration profile and $\mathrm{KL}_{\mathrm{a}}$ in solid-state fermentation. Process Biochemistry 36, 9-18, 2000. doi:10.1016/S0032-9592(00)00156-4 C362

[21] P. M. Doran. Bioprocess engineering principles. vol. 1, Academic Press 1995. C361

[22] U. Grigull. team tables in SI-units: concise steam tables in SI-units (student's tables). Properties of ordinary water substance up to $1000^{\circ} \mathrm{C}$ and 100 megapascal. Springer 1990. C361

[23] L. Ikasari and D. A. Mitchell. Oxygen uptake kinetics during solid state fermentation with Rhizopus oligosporus. Biotechnology techniques 12, 171-175, 1998. doi:10.1023/A:1008805004361 C363

[24] A. Pandey. Recent process developments in solid-state fermentation. Process Biochemistry 27, 109-117, 1992. doi:10.1016/0032-9592(92)80017-W C365 
[25] B. K. Lonsane, B. K and G. Saucedo-Castaneda and M. Raimbault and S. Roussos and G. Viniegra-Gonzalez and N. P. Ghildyal and M. Ramakrishna and M. M. Krishnaiah. Scale-up strategies for solid state fermentation systems. Process Biochemistry 27(5), 259-273, 1992.. doi:10.1016/0032-9592(92)85011-P C355, C365

[26] B. R. Holland and J. Schmid. Selecting representative model micro-organisms. BMC microbiology 5(1) 26-30, 2005. doi:10.1186/1471-2180-5-26 C361

\section{Author addresses}

1. Raja Mahanama, School of Chemical and Biomolecular Engineering, The University of Sydney, Sydney 2006, NSW, Australia. mailto:raja.mahanama@sydney.edu.au

2. Aydin Berenjian, School of Chemical and Biomolecular Engineering, The University of Sydney, Sydney 2006, NSW, Australia. mailto:aydin. berenjian@sydney.edu.au

3. Hub Regtop, Agricure Scientific Organics, Lot 6 Gantry, Pl Braemar, NSW 2575, Australia. mailto:hub@agricure.com.au

4. Andrea Talbot, Agricure Scientific Organics, Lot 6 Gantry, Pl Braemar, NSW 2575, AUSTRALIA. mailto:andrea@agricure.com.au

5. Fariba Dehghani, School of Chemical and Biomolecular Engineering, The University of Sydney, Sydney 2006, NSW, Australia. mailto:fariba.dehghani@sydney.edu.au

6. John Kavanagh, School of Chemical and Biomolecular Engineering, The University of Sydney, Sydney 2006, NSW, Australia. mailto: john. kavanagh@sydney.edu . au 